\title{
RANCANG BANGUN ELECTRIC CONTAINER CRANE SEBAGAI SARANA BONGKAR MUAT DI TERMINAL PETIKEMAS BERBASIS PLC OMRON CP1E
}

(Design of Electric Container Crane As Loading and Unloading Equipment at Container Terminals Based PLC OMRON CP1E)

\author{
EDDO MAHARDIKA ${ }^{1}$, RANDY ANDRIAN SUBIYANTO ${ }^{2}$, \\ \& DWI SONGGO PANGGAYUDI \\ Jurusan Teknik Elektro, Fakultas Teknik, Universitas Muhammadiyah Suabaya \\ Jalan Sutorejo No. 59 Surabaya \\ Email: eddo.hutama@gmail.com ${ }^{1)}$ randyandrian2@gmail.com ${ }^{2)}$
}

\begin{abstract}
Port is one of the supporting infrastructure of sea transportation which is the gateway to and out of goods and passengers. The function and role of the port is very important one of them is the container terminal. The container terminal is where loading and unloading of goods in containers. At the container terminal the length of loading and unloading process is determined by the quality and quantity of the tool. One of them is container crane. Therefore designed a container crane model in the form of a prototype named electric container crane. At the time of design is used Programmable Logic Controller (PLC) Omron brand CP1E-E20SDRA type as a safety controller and add a double trolley system so that container cranes can be flexible in 4 slots without gantry movement, and also add automatic cable track system so container crane can be Moving without the need for a portable generator because it is supplied directly using electricity from PLN.
\end{abstract}

Keyword: Container Crane, Programmable Logic Controller (PLC), Trolley, Gantry, Cable Track.

\begin{abstract}
ABSTRAK
Pelabuhan adalah salah satu infrastruktur penunjang transportasi laut yang merupakan pintu gerbang keluar masuk barang dan penumpang. Fungsi dan peran pelabuhan sangat penting salah satunya adalah terminal petikemas. Terminal petikemas merupakan tempat bongkar muat barang dalam petikemas. Pada terminal petikemas lamanya proses bongkar muat ditentukan oleh kualitas dan kuantitas alat. Salah satunya adalah container crane. Oleh karena itu dirancang sebuah model container crane dalam bentuk prototype yang diberi nama electric container crane. Pada saat perancangan digunakan Programmable Logic Controller (PLC) merek Omron tipe CP1E-E20SDRA sebagai pengontrol kemanan dan menambahkan sistem double trolley supaya container crane dapat beregerak secara fleksibel sejauh 4 slot tanpa melakukan pergerakan gantry, serta menambahkan juga sistem cable track otomatis supaya container crane dapat bergerak tanpa memerlukan generator portabel karena disuplai langung menggunakan listrik dari PLN.
\end{abstract}

Kata Kunci: Container Crane, Programmable Logic Controller (PLC), Trolley, Gantry, Cable Track. 


\section{PENDAHULUAN}

Pelabuhan adalah salah satu infrastruktur penunjang transportasi laut yang merupakan pintu gerbang keluar masuk barang dan penumpang. Fungsi dan peran pelabuhan sangat penting dalam mendukung sistem transportasi untuk pengembangan suatu wilayah salah satu-nya adalah terminal petikemas. Terminal peti-kemas sendiri merupakan salah satu fasilitas pelabuhan yang digunakan untuk proses bongkar muat barang dalam petikemas. Lamanya proses penumpukan petikemas bergantung pada beberapa faktor, salah satunya adalah kuali-tas dan kuantitas peralatan yang ada. Maka dari itu sejarah Container Crane dimulai.

Namun dari berbagai hasil industri pembuatan container crane belum bisa begergerak fleksibel. Maka dari itu pada penelitian ini penelitian ini dirancang sebuah model Container Crane untuk pengangkatan dan pemindahan Petikemas. Model container crane ini, dirancang dengan double trolley sehingga pergerakannya akan lebih fleksibel. Kemudian untuk supply tenaga listrik didesain menggunakan gulungan kabel otomatis sehingga seluruh kebutuhan supply listrik tidak lagi menggunakan sumber dari generator portable. Pada penelitian kali ini kali ini, digunakan motor DC sebagai penggerak dan kontrol sistem kendali pengamanya menggunakan Programmable Logic Controller (PLC) ditambah relay-relay untuk pensaklaran.

\section{TINJAUAN PUSTAKA \\ a. Pengertian Crane}

Menurut Wijayanto dan Susatio (2012), menyatakan bahwa gantry crane adalah suatu alat yang digunakan untuk mengangkat atau memindahkan muatan berat dan banyak digunakan di pelabuhan untuk proses loadingunloading container.

\section{b. Motor Listrik Arus Searah (DC)}

Motor listrik arus searah adalah jenis mo-tor listrik yang beroperasi dengan sumber te-gangan arus listrik searah DC (Direct Current). Motor DC memerlukan suplai tegangan yang searah pada kumparan medan untuk diubah menjadi energi mekanik. Perubahan ini dilakukan dengan mengubah tenaga listrik menjadi magnet yang disebut sebagai elektro magnet. Sebagaimana kita ketahui bahwa kutub-kutub dari magnet yang senama akan tolak-menolak dan kutub-kutub tidak senama, tarik-menarik. Maka kita dapat memperoleh gerakan jika kita menempatkan sebuah magnet pada sebuah poros yang dapat berputar, dan magnet yang lain pada suatu kedudukan yang tetap.

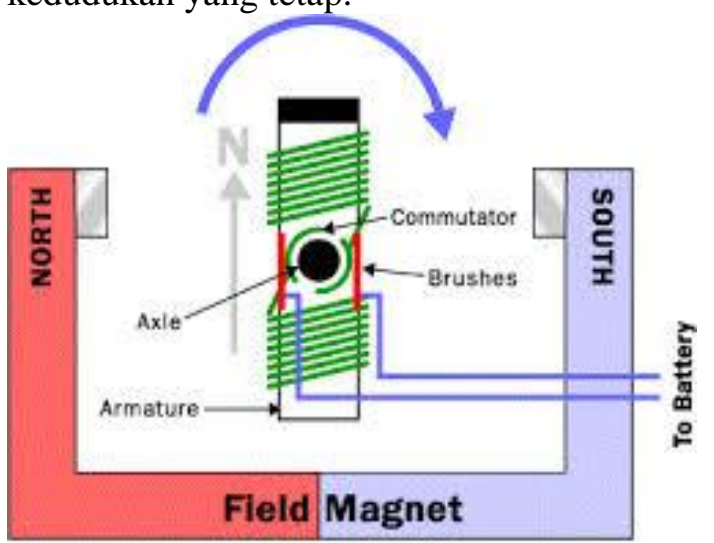

Gambar 2.1 Prinsip Kerja Motor Listrik Sumber: Elektronika Dasar (2012)

\section{1) Prinsip Kerja Motor DC}

Jika arus lewat pada suatu konduktor, timbul medan magnet di sekitar konduktor. Arah medan magnet ditentukan oleh arah aliran arus pada konduktor.

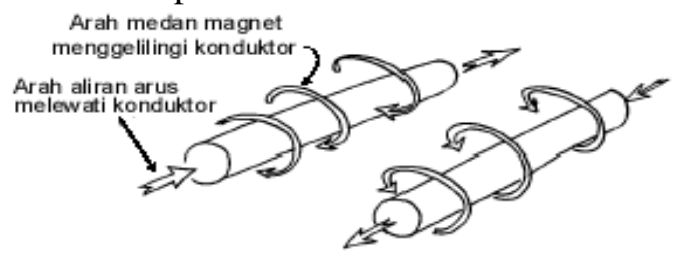

Gambar 2.2 Medan magnet yang membawa arus yang mengelilingi konduktor. Sumber: Zuhal (1988).

Pada motor listrik konduktor berbentuk $\mathrm{U}$ disebut angker dinamo.

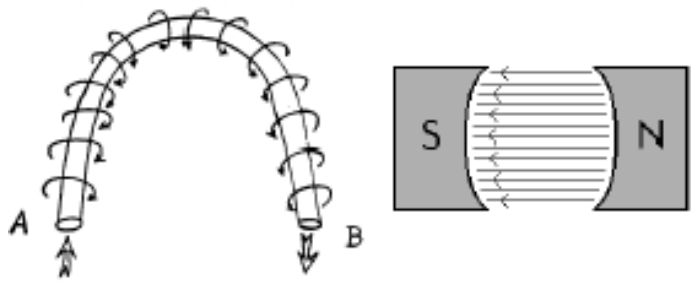

Gambar 2.3 Medan magnet mengelilingi konduktor dan diantara kutub. Sumber: Zuhal (1988)

Medan konduktor A akan menambah medan pada kutub dan menimbulkan medan yang kuat di bawah konduktor. Konduktor akan berusaha bergerak ke atas untuk keluar dari medan kuat ini. Medan konduktor B yang berlawanan arah jarum jam akan menambah medan pada kutub dan menimbulkan medan yang kuat di atas konduktor. Konduktor akan 
berusaha untuk bergerak turun agar keluar dari medan yang kuat tersebut. Gaya-gaya tersebut akan membuat angker dinamo berputar.

\section{2) Mengatur Kecepatan Pada Armature}

Motor DC yang digunakan pada robot beroda umumnya adalah motor DC dengan magnet permanen. Motor DC jenis ini memiliki dua buah magnet permanen. Di dalam medan magnet inilah jangkar/rotor berputar. Jangkar yang terletak di tengah motor memiliki jumlah kutub yang ganjil dan pada setiap kutubnya terdapat lilitan. Lilitan ini terhubung ke area kontak yang disebut komutator. Sikat (brushes) yang terhubung ke kutub positif dan negatif motor memberikan daya ke lilitan sedemikian rupa sehingga kutub yang satu akan ditolak oleh magnet permanen yang berada di dekatnya, sedangkan lilitan lain akan ditarik ke magnet permanen yang lain sehingga menyebabkan jangkar berputar. Kecepatan putar motor DC $(\mathrm{N})$ dirumuskan dengan Persamaan berikut. (Fahmizal, 2011)

$$
\mathrm{N}=\frac{V_{T M-I_{a} \cdot R_{a}}}{K \Phi}
$$

Keterangan:

$\mathrm{V}_{\mathrm{TM}}=$ Tegangan Terminal

$\mathrm{I}_{\mathrm{a}} \quad=$ Arus Jangkar Motor

$\mathrm{R}_{\mathrm{a}}=$ Hambatan Jangkar Motor

$\mathrm{K}=$ Konstanta Motor

$\Phi=$ Fluk Magnet Yang Terbentuk Pada Motor

\section{3) Motor DC Dengan Magnet Permanen}

Dalam motor ini, armature berputar didalam medan magnet. Prinsip kerjanya adalah ketika konduktor yang dialiri arus listrik diletakkan didalam medan magnet maka akan ada gaya mekanik yang alami konduktor tersebut.

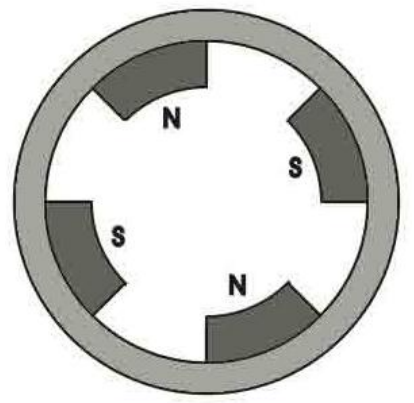

Gambar 2.4 Motor DC dengan magnet permanen. Sumber: Fahmizal (2011)

Magnet permanen dipasang sedemikian rupa sehingga kutup $\mathrm{N}$ dan $\mathrm{S}$ dari masing- masing magnet berlawanan dengan armature. Rotor pada motor DC dengan magnet permanen atau disebut juga dengan angker terdiri dari inti, gulungan, dan komutator. Dan apabila rotor dipasok arus listrik maka akan menimbul-kan gaya mekanik.

Seperti dengan motor DC yang lainnya, untuk menghitung tegangan yang di-supply, rugi daya pada jangkar, dan besarnya gaya gerak listrik (ggl) maka dapat dihitung dengan rumus dibawah ini.

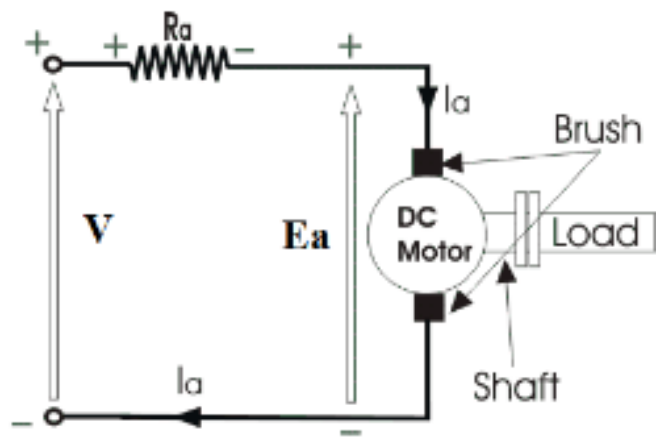

Gambar 2.5 Rangkaian motor DC dengan magnet permanen. Sumber: Fahmizal (2011)

$$
\mathrm{V}=\mathrm{Ea}+\mathrm{Ia} \times \mathrm{Ra}
$$

Keterangan:

$\mathrm{V}$ = Tegangan input (Volt)

$\mathrm{Ea}=$ Gaya gerak listrik (Volt)

Ia = Arus pada armature (Ampere)

$\mathrm{Ra}=$ Resistansi pada armature $(\Omega)$

Untuk menghitung kerugian daya karena panas pada lilitan armature maka,

$$
P_{R u g i}=I_{a}^{2} \times R_{a}
$$

Kemudian daya mekanis yang dibutuhkan untuk menghasilkan torsi motor DC dengan megnet permanen adalah:

$$
P_{m}=E_{a} \times I_{a}
$$

Sehingga perbandingan keluaran daya motor yang digunakan terhadap keluaran daya totalnya adalah:

$$
\eta=\frac{\mathrm{Ea} \times \mathrm{Ia}}{\mathrm{V} \times \mathrm{Ia}} \times 100 \%
$$

\section{c. Tali Kawat}

Ada 2 jenis tali yang dikenal pada saat ini, yaitu: a) Tali nonmetal, misalnya tali rami atau manila henep dan belakang tali plastik yang telah dikembangkan; dan b) Tali baja (steel wirerope) yang terbuat dari serat-serat baja.

\section{1) Tali Baja (Wirerope)}

Tali baja berfungsi untuk mengangkat dan menurunkan beban serta digunakan secara luas pada mesin-mesin pengangkut 
sebagai perabot pengangkat, tali baja adalah tali yang dikonstruksikan dari kumpulan jalinan serat-serat baja (steel wire) dengan kekuatan $\sigma \mathrm{b}=130-200 \mathrm{~kg} / \mathrm{mm} 2$.

Beberapa serat dipintal hingga menjadi sa-tu jalinan (strand), kemudian beberapa strand dijalin pula pada suatu inti (core) sehingga membentuk tali.
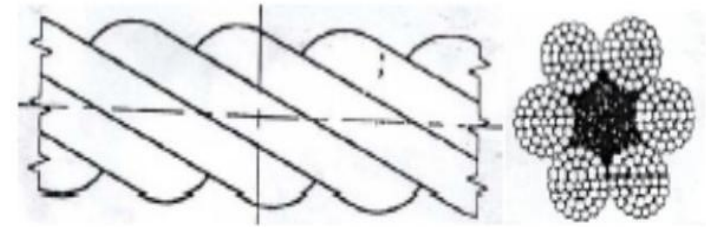

Gambar 2.6 Konstruksi Serat Tali Baja. Sumber: Rudenko, N (1992)

\section{2) Tali Untuk Crane Pengangkat}

Pada umumnya setiap tali hanya dapat mengalami lengkungan tertentu sepanjang umur pakai, sejumlah lengkungan tertentu yang telah melewati batas ini akan rusak dengan cepat.

Satu lengkungan diasumsikan sebagai perubahan tali dari kedudukan lurus, menjadi kedudukan melengkung, atau dari kedudukan lurus menjadi melengkung. Jumlah lengkungan yang di tentukan oleh jumlah titik (puli atau drum) tempat tali lewat, lengkungan dalam satu arah.

Pada titik tersebut setara dengan lengkungan tunggal dan lengkungan variabel setara dengan lengkungan ganda sistem puli yang banyak digunakan dan jumlah lengkungan dapat dilihat pada gambar di bawah ini.

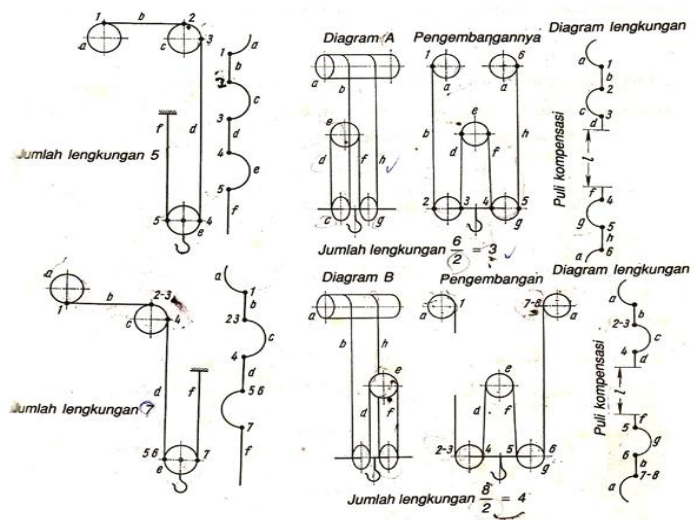

Gambar 2.7 Menentukan Jumlah Lengkungan Tali dengan satu puli bergerak dan Puly Majemuk. Sumber: Rudenko, N (1992)

\section{3) Tarikan Kerja Maksimum Tali}

Tarikan kerja maksimum pada tali ditentukan oleh sistem puli beban SW dihitung dengan rumus: (Rudenko, 1992)
Keterangan:

$$
\mathrm{S}=\frac{Q}{n \eta_{p} \cdot \eta_{1}}
$$

$\mathrm{Q}=$ Berat muatan yang diangkat $(\mathrm{kg})$

$\mathrm{N}=$ Jumlah puli penumpu $\mathrm{n}=8$

$\eta \quad=$ Efisiensi puli $=0,873$

$\eta p=$ Efisieni yang disebabkan kerugian tali akibat kekakuannya ketika menggulung pada drum yang diasumsikan 0,98

(d) Tarikan pada Satu Bagian Tali

Tarikan kerja pada satu bagian tali ditentukan oleh sistem puli beban SW dihitung dengan rumus: (Rudenko, 1992)

Keterangan:

$$
\mathrm{P}=\frac{\mathrm{Q}}{\mathrm{Z} \times \eta}
$$

$\mathrm{P} \quad=$ Tarikan pada satu bagian tali $(\mathrm{kg})$

$\mathrm{Q} \quad=$ Berat muatan yang diangkat $(\mathrm{kg})$

$\mathrm{Z} \quad$ = Jumlah puli penumpu

$\eta \quad=$ Efisiensi puli $(0,873)$

(e) Nilai Beban Putus Pada Tali

Nilai beban putus pada tali ditentukan oleh sistem puli beban SW dihitung dengan rumus: (Rudenko, 1992)

$$
\mathrm{S}=\mathrm{P} \times \mathrm{K}
$$

Keterangan:

$\mathrm{S}=$ Nilai beban putus pada tali $(\mathrm{kg})$

$\mathrm{P} \quad=$ Tarikan pada satu bagian tali $(\mathrm{kg})$

$\mathrm{K}=$ Nilai factor keamanan untuk crane $(5,5)$

d. Programmable Logic Controller (PLC)

PLC adalah suatu perangkat elektronika yang mengontrol mesin dan proses pengendalian yang menggunakan memori dan dapat diprogram untuk menyimpan instruksi (perintah) dan menjalankan "Spesific Function" termasuk ON-OFF, Control.

\section{1) Prinsip Kerja PLC}

Prinsip kerja sebuah PLC adalah menerima sinyal masukan proses yang dikendalikan lalu melakukan serangkaian instruksi logika terhadap sinyal masukan tersebut sesuai dengan program yang tersimpan dalam memori lalu menghasilkan sinyal keluaran untuk mengendalikan aktuator atau peralatan lainnya.

PLC memiliki dua bagian dasar, yaitu: input/output interface system dan central processing unit. 


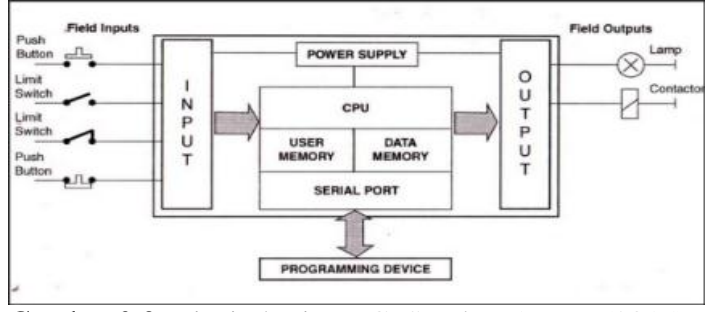

Gambar 2.8 Prinsip kerja PLC. Sumber:Anwar (2015).

2) Bagian-Bagian Umum PLC OMRON $C P 1 E$

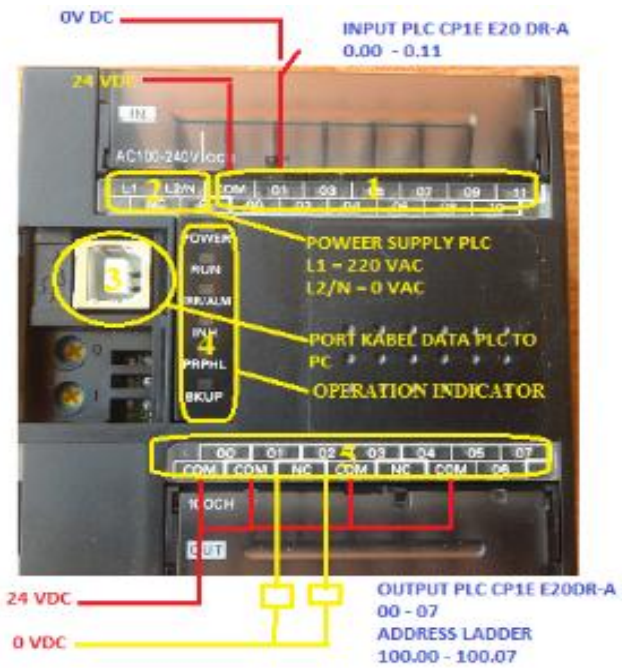

Gambar 2.9 Bagian-Bagian PLC OMRON Sysmac CP1E. Sumber: OMRON (2004)

1. Blok eksternal power supply 12 VDC-24 VDC, ground dan input terminal.

2. Block terminal power supply $220 \mathrm{VAC}$.

3. Peripheral USB port untuk mengubungkan dengan komputer dan komputer dapat digunakan untuk memprogram dan memonitoring.

4. Operation indicator, mengidentifikasi status operasi dari CP1E termasuk power status, mode operasi, errors, dan komunikasi USB.

5. Blok eksternal power supply 12 VDC-24 VDC, ground dan output terminal

\section{METODE PENELITIAN}

\section{a. Waktu dan Tempat Penilitian}

Waktu Penelitian pada 15 Maret - 14

Mei 2017 bertempat di PT Nilam Port Terminal Indonesia Jalan Nilam Timur Tanjung Perak Surabaya.

\section{b. Diagram Alir Penelitian}

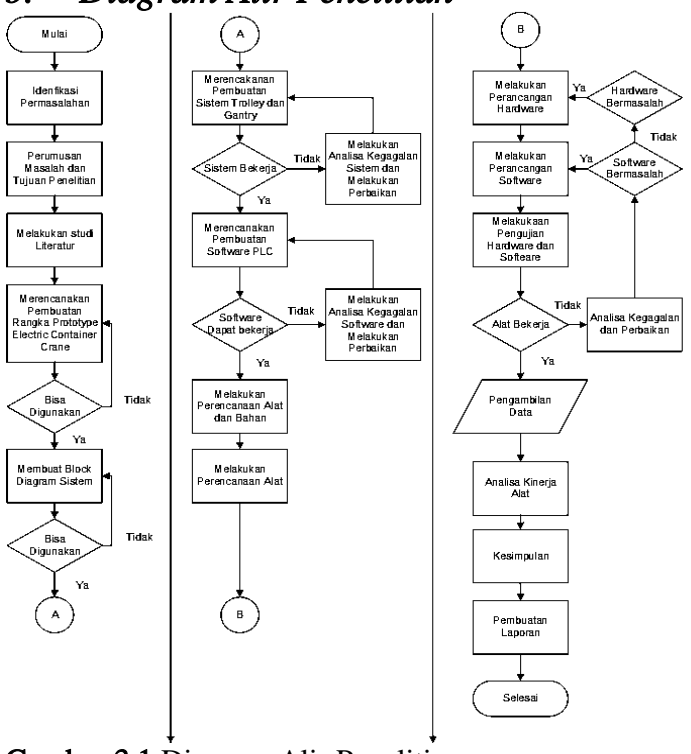

Gambar 3.1 Diagram Alir Penelitian.

Sumber: Peneliti (2017)

\section{1) Identifikasi Permasalahan}

Hal yang paling awal harus dilakukan sebelum melakukan penelitian adalah melakukan identifikasi permasalahan. Identifikasi permasalahan dilakukan menggunakan cara melakukan pengamatan langsung pada Rubber Tyre Gantry Crane ZPMC.

\section{2) Perumusan Masalah dan Tujuan Pene- litian}

Saat melakukan identifikasi permasalahan peneliti masih menemukan kekurangankekurangan pada alat. Maka dari itu peneliti akan melakukan pengkajian masalah yang didapat dari identifikasi permasalahan dan menentukan tujuan dari penelitian yang dilakukan.

\section{3) Studi literatur}

Studi literatur ini bertujuan untuk mendapatkan informasi berupa teori-teori maupun studi kasus yang dapat dijadikan pedoman dalam penulisan dan penyusuan penelitian ini. Literatur ini dapat berupa buku, karya-karya ilmiah, jurnal maupun artikel-artikel yang ada di internet serta media yang berhubungan dengan penulisan penelitian ini. 
4) Merencanakan Pembuatan Rangka Prototype

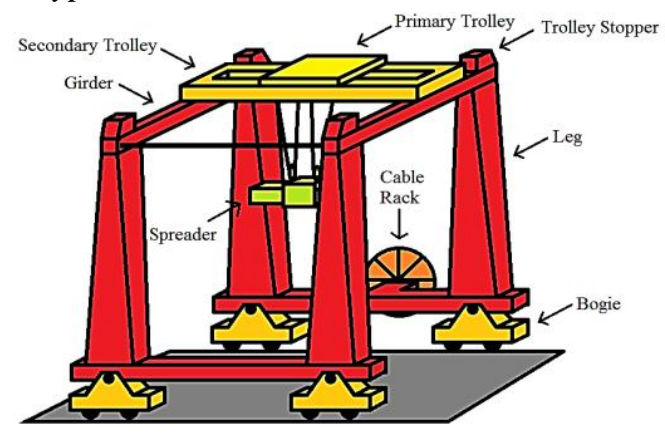

Gambar 3.2 Perancangan kerangka Electric Container Crane. Sumber: Peneliti (2017)

Sebelum melakukan perancangan alat peneliti perlu merencanakan kerangka alat yang akan dibuat. Kerangka dapat digambarkan seperti pada gambar 3.2 diatas.

(a) Merencanakan Block Diagram Sistem

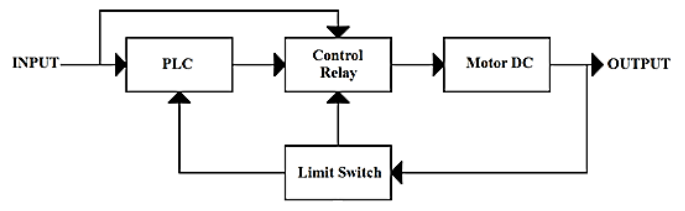

Gambar 3.3 Blok Diagram Sistem

Sumber: Peneliti (2017)

Setelah merencanakan pembuatan rangka electric container peneliti perlu merencanakan blok diagram sistem. Sehingga ketika sistem dipasangkan pada hardware alat dapat bekerja dengan baik. Sistem yang akan dibuat digambarkan seperti pada gambar 3.3 diatas.

(b) Pengadaan Komponen

Tabel 3.1 Kebutuhan Bahan

\begin{tabular}{|c|c|c|c|}
\hline No & Bahan & Spesifikasi & Jumlah \\
\hline 1 & Acrylic & 3 & $200 \times 100 \mathrm{~cm}$ \\
\hline 2 & Motor Gantry & DC 25GA370 12V 100RPM & 4 \\
\hline 3 & Motor Trolley Primer & DC 37GB31ZY 12V 110RPM & 2 \\
\hline 4 & Motor Trolley Sekunder & DC 25GA370 12V 450RPM & 2 \\
\hline 5 & Motor Kabel Rack & DC 38GB31ZY 12V 110RPM & 1 \\
\hline 6 & Relay 12V DC & $\begin{array}{c}\text { ZD-3FF-S-1Z-T 12 VDC } \\
\text { 7A 250 VAC } \\
\text { 12A 14 VDC } \\
\end{array}$ & 23 \\
\hline 7 & Limit Switch & - & 8 \\
\hline 8 & PCB Board & - & 5 \\
\hline 9 & Kabel & - & 2 Rol \\
\hline 10 & Transformator 1A & $\begin{array}{c}\text { CT 1A } \\
\text { VIN 110VAC/220VAVOUT } \\
12 / / 9 / 6 / 0 \mathrm{VDC} \\
\end{array}$ & 1 \\
\hline 11 & Transformator 3A & $\begin{array}{c}\text { CT 3A } \\
\text { VIN 110VAC/220VAVOUT } \\
\text { 12//9/6/0VDC } \\
\end{array}$ & 1 \\
\hline 12 & PLC & OMRON CP1E-E20SDR-A & 1 \\
\hline 13 & Lem & - & 20 \\
\hline 14 & Lampu LED & Lampu Led 5VDC & - \\
\hline 15 & Fuse & $2 \mathrm{~A}$ & 2 \\
\hline 16 & Push Button & - & 15 \\
\hline 17 & Button Push On & - & 4 \\
\hline
\end{tabular}

(c) Perancangan Hardware

Setelah semua perencanaan diatas selesai tindakan yang dilakukan adalah membuat hardware sesuai dengan rangka pada gambar diatas menggunakan alat dan bahan yang sudah disediakan. Berikut adalah langkahlangkah perancangan hardware:

1. Merancang kaki-kaki (leg) electric container crane

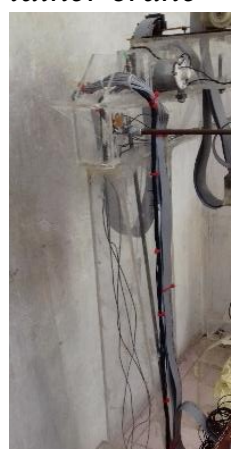

Gambar 3.4 Leg (Kaki Electric Container Crane). Sumber: Peneliti (2017)

2. Merancang kerangka gantry

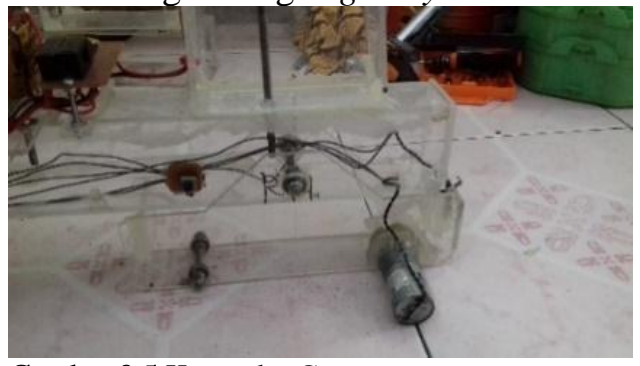

Gambar 3.5 Kerangka Gantry.

Sumber: Peneliti (2017)

3. Merancang kerangka trolley

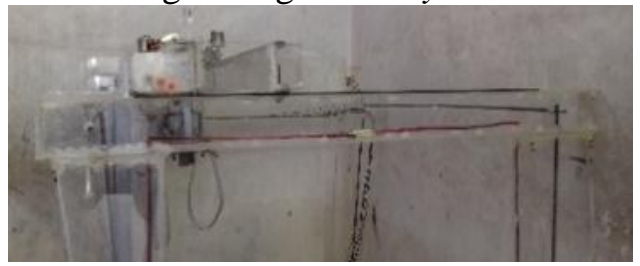

Gambar 3.6 Kerangka Trolley.

Sumber: Peneliti (2017)

4. Merancang cable track

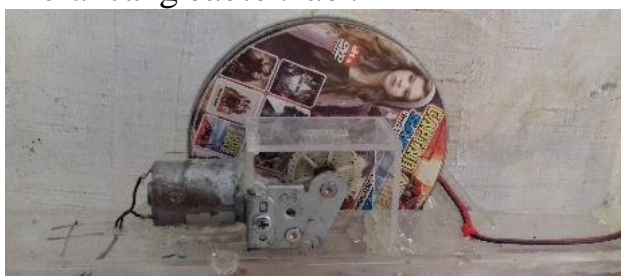

Gambar 3.7 Cable Track. Sumber: Peneliti (2017)

5. Merancang console atau remot pengontrol electric container crane. 


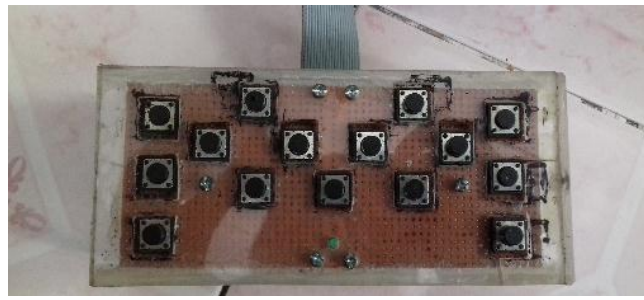

Gambar 3.8 Console. Sumber: Peneliti (2017)

6. Merangkai relay pengontrol dan pengkabelan pada setiap komponen pada electric container crane.

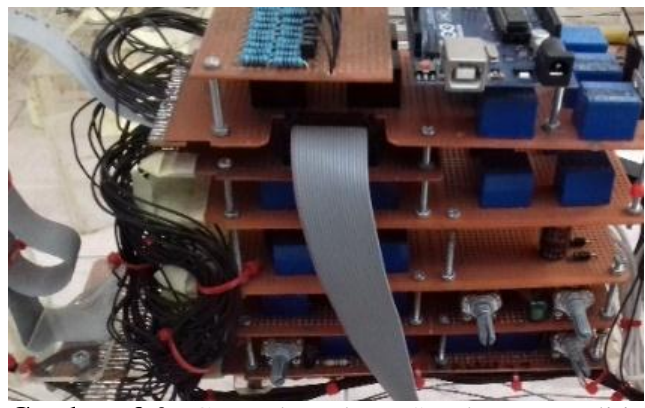

Gambar 3.9 Control Relay. Sumber: Peneliti (2017)

7. Merangkai PLC sebagai pengontrol alat

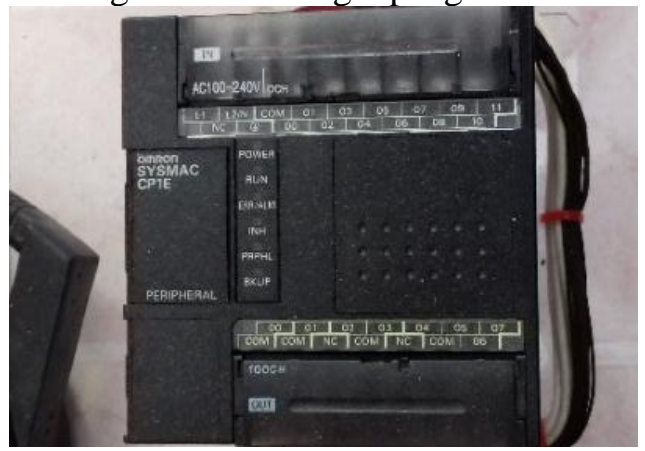

Gambar 3.10 Pemasangan PLC.

Sumber: Peneliti (2017)

8. Memasang dan perangkaian Power

Supply

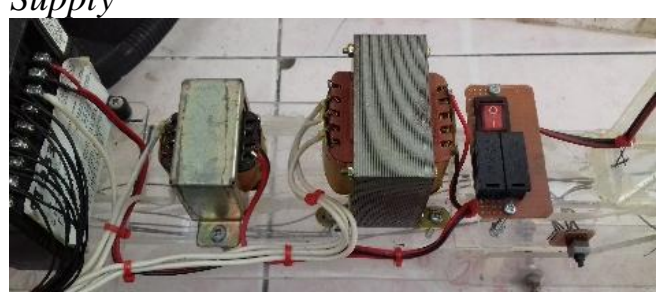

Gambar 3.11 Power Supply.

Sumber: Peneliti (2017)

(d) Pengujian Hardware dan Software

Pada tahap ini dilakukan pengujian terhadap sistem yang dibuat sehingga dapat ditemukan permasalahan dan dilakukan perbaikan. Pengujian dilakukan pada perangkat keras (hardware), perangkat lunak (software), dan sistem integrasi. Tujuannya adalah mengetahui kinerja sistem yang telah dibuat dan memberikan analisa dari hasil pengujian. Usaha ini dilakukan juga untuk mengetahui kemampuan alat uji yang telah dibuat, apakah sudah meme-nuhi keinginan atau belum. Pengujian ini dila-kukan beberapa kali untuk mendapatkan hasil yang baik.

(e) Analisa Kegagalan dan Tindakan Perbaikan

Tidak selamanya pengujian sistem alat bisa langsung mendapatkan hasil yang memuaskan. Oleh karena itu apabila ditemui hasil yang tidak sesuai perlu dilakukan analisa kegagalan dan tindakan perbaikannya.

(f) Analisa Kerja Alat

Dalam pengambilan data kita bisa mengetahui apakah alat uji bisa berfungsi dengan baik dengan melihat hasil/data yang diambil. Apakah terjadi penyimpangan yang cukup signifi-kan diantara data-data yang sama, atau hasil yang diambil merupakan data yang relatif sama.

\section{HASIL DAN PEMBAHASAN \\ a. Motor Gantry}

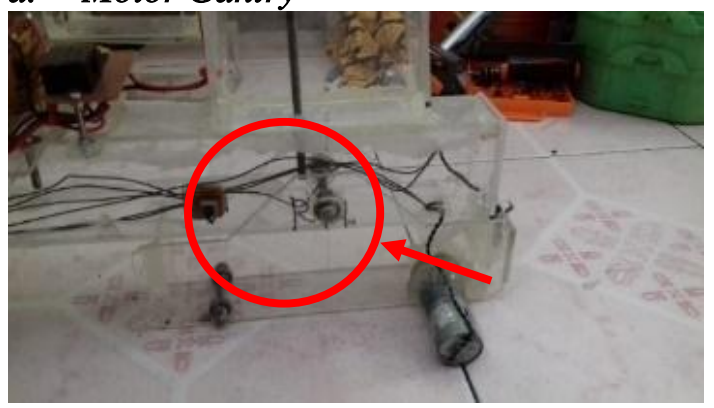

Gambar 4.1 Motor Gantry

Sumber: Peneliti (2017)

Spesifikasi motor gantry

Tipe : DC 25GA370 12V 100RPM

Tegangan : DC 12 Volt

Arus Kerja Maksimal : 0,8 Ampere

Putaran RPM : 100 RPM

Tabel 4.1 data hasil uji coba motor gantry
\begin{tabular}{|c|c|c|c|c|c|c|c|}
\hline $\begin{array}{c}\text { Beban } \\
\text { (Kg) }\end{array}$ & $\begin{array}{c}\text { Tegangan } \\
\text { (V) }\end{array}$ & $\begin{array}{c}\text { Ia } \\
(\mathrm{A})\end{array}$ & $\begin{array}{c}\text { Ra } \\
(\mathbf{\Omega})\end{array}$ & $\begin{array}{c}\mathbf{E a} \\
(\mathrm{V})\end{array}$ & $\begin{array}{c}\text { Pm } \\
(\mathrm{W})\end{array}$ & $\begin{array}{c}\text { Efisiensi } \\
(\%)\end{array}$ & $\begin{array}{c}\text { Kecepatan } \\
\text { Putaran } \\
\text { Motor } \\
\text { (RPM) }\end{array}$ \\
\hline 3,5 & 11,52 & 0,05 & 15,1 & 10,765 & 0,538 & 93,4 & 90 \\
\hline
\end{tabular}

Sumber: Peneliti (2017)

Perhitungan gaya gerak listrik (Ea), daya mekanik $\left(P_{m}\right)$, efisiensi $(\eta)$, kecepatan putar motor (RPM).

a. Perhitungan emf (Ea)

$$
\begin{aligned}
& \mathrm{V}=\mathrm{Ea}+\mathrm{Ia} \cdot \mathrm{Ra} \\
& 11,52 \mathrm{~V}=\mathrm{Ea}+0,05.15,1
\end{aligned}
$$


$\mathrm{Ea}=11,52 \mathrm{~V}-0,755 \mathrm{~V}$

$\mathrm{Ea}=10,765 \mathrm{~V}$

b. Perhitungan daya input

Pin $=\mathrm{V} \times \mathrm{Ia}$

Pin $=11,52 \times 0,05$

Pin $=0,576$ Watt

c. Perhitungan daya mekanik $(\mathrm{Pm})$

$\mathrm{Pm}=\mathrm{Ea} \times \mathrm{Ia}$

$\mathrm{Pm}=10,765 \times 0,05$

$\mathrm{Pm}=0,538 \mathrm{Watt}$

d. Perhitungan Efisiensi motor $(\eta)$

$\eta=$ P_Out $/$ Pin $\times 100 \%$

$\eta \quad=0,538 / 0,576 \times 100 \%$

$\eta=0,9340277 \times 100 \%=93,4 \%$

e. Perhitungan kecepatan putar motor $(\mathrm{N})$

$\mathrm{N}=\frac{V_{T M-I_{a} \cdot R_{a}}}{K \Phi}$

Sesuai spesifikasi motor yang digunakan jika motor gantry tanpa beban maka diasumsikan $\mathrm{V}=$ Ea karena Ia $=0$ dan putaran motor adalah 100 RPM. Maka perhitungan menjadi $100=\frac{12-(0 \times 15,1)}{K \Phi}$

$100=\frac{12-0}{K \Phi}$

$\mathrm{K} \Phi=\frac{12}{100}$

$\mathrm{K} \Phi=0,12$ Webber

Dari perhitungan diatas diperoleh besar $\mathrm{K} \varphi$ adalah sebesar 0,12 Webber. Kemudian jika motor gantry terbebani seberat $3,5 \mathrm{~kg}$ maka perhitungan putaran motor menjadi

$$
\begin{aligned}
N & =\frac{11,52-(0,05 \times 15,1)}{0,12} \\
N & =\frac{11,52-0,755}{0,12} \\
N & =\frac{10,765}{0,12} \\
N & =89,708 \mathrm{RPM}
\end{aligned}
$$

Dari perhitungan diatas didapatkan putaran motor menjadi 90 putaran per menit (RPM).

\section{b. Cable Track}

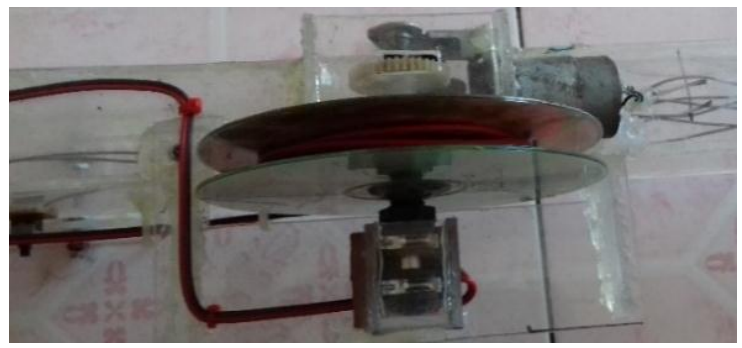

Gambar 4.2 Cable Track. Sumber: Peneliti (2017)

Spesifikasi motor Cable Track

Tipe : DC 37GB31ZY 12V 110RPM
Tegangan : DC 12 Volt

Arus Kerja Maksimal : 0,1 Ampere

Putaran RPM: 110 RPM

Tabel 4.2 data hasil uji coba motor cable track

\begin{tabular}{|c|c|c|c|c|c|c|}
\hline $\begin{array}{c}\text { Tegangan } \\
\text { (V) }\end{array}$ & $\begin{array}{c}\text { Ia } \\
(\mathrm{A})\end{array}$ & $\begin{array}{c}\text { Ra } \\
(\mathbf{\Omega})\end{array}$ & $\begin{array}{c}\boldsymbol{E} \boldsymbol{a} \\
\text { (V) }\end{array}$ & $\begin{array}{c}\text { Pm } \\
\text { (W) }\end{array}$ & $\begin{array}{c}\text { Effisiensi } \\
\text { (\%) }\end{array}$ & $\begin{array}{c}\text { Kecepatan } \\
\text { Putaran } \\
\text { Motor } \\
\text { (RPM) }\end{array}$ \\
\hline 11,21 & 0,026 & 123,8 & 7,86 & 0,291 & 70,1 & 73 \\
\hline
\end{tabular}

Sumber: Peneliti (2017).

Perhitungan gaya gerak listrik (Ea), daya mekanik $\left(P_{m}\right)$, efisiensi $(\eta)$, kecepatan putar motor (RPM).

a. Perhitungan emf (Ea)

$$
\begin{array}{ll}
\mathrm{V} & =\mathrm{Ea}+\mathrm{Ia} . \mathrm{Ra} \\
11,21 \mathrm{~V} & =\mathrm{Ea}+0,026 \times 123,8 \\
11,21 \mathrm{~V} & =\mathrm{Ea}+3,3488 \mathrm{~V} \\
\mathrm{Ea} & =11,21 \mathrm{~V}-3,3488 \mathrm{~V} \\
\mathrm{Ea} & =7,8612 \mathrm{~V}
\end{array}
$$

b. Perhitungan daya input

$$
\begin{aligned}
\text { Pin } & =\mathrm{V} \times \mathrm{Ia} \\
\text { Pin } & =11,21 \times 0,026 \\
\text { Pin } & =0,291 \text { Watt }
\end{aligned}
$$

c. Perhitungan daya mekanik (Pm)

$$
\begin{aligned}
\mathrm{Pm} & =\text { Ea } \times \mathrm{Ia} \\
\mathrm{Pm} & =7,8612 \times 0,026 \\
\mathrm{Pm} & =0,204 \text { Watt }
\end{aligned}
$$

d. Perhitungan Efisiensi motor ( $(\mathrm{n})$

$$
\begin{aligned}
\eta & =\frac{P_{\text {Out }}}{P_{\text {in }}} \times 100 \% \\
\eta & =\frac{0,204}{0,291} \times 100 \% \\
\eta & =0,7010309 \times 100 \%=70,1 \%
\end{aligned}
$$

e. Perhitungan kecepatan putar motor $(\mathrm{N})$

$$
\mathrm{N}=\frac{V_{T M-I a \cdot R a}}{K \Phi}
$$

Sesuai spesifikasi motor yang digunakan jika motor cable track tanpa beban maka diasumsikan $\mathrm{V}=$ Ea karena Ia $=0$ dan putaran motor adalah 110 RPM. Maka perhitungan menjadi

$$
\begin{aligned}
110 & =\frac{12-(0 \times 123,8)}{110} \\
110 & =\frac{12-0}{K \Phi} \\
K \Phi & =\frac{12}{110} \\
K \Phi & =0,109 \text { Webber }
\end{aligned}
$$

Dari perhitungan diatas diperoleh besar $\mathrm{K} \varphi$ adalah sebesar 0,109 Webber. Maka perhitungan motor menjadi

$$
\begin{aligned}
& \mathrm{N}=\frac{11,21-(0,026 \times 123,8)}{0,109} \\
& \mathrm{~N}=\frac{11,21-3,2188}{0,109}
\end{aligned}
$$


$\mathrm{N}=\frac{7,9912}{0,109}$

$\mathrm{N}=73,31 \mathrm{RPM}$

Dari perhitungan diatas didapatkan putaran motor menjadi 73 putaran per menit (RPM).

\section{c. Trolley}

1) Motor Trolley Primer

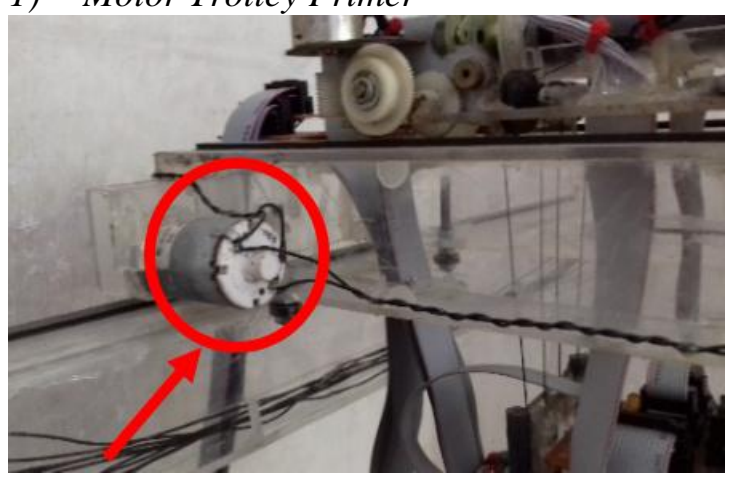

Gambar 4.3 Motor Trolley Primer.

Sumber: Peneliti (2017)

Spesifikasi Motor Trolley Primer

Tipe : DC 37GC31ZY 12V 110RPM

Tegangan : DC 12 Volt

Arus Kerja Maksimal : 0,3 Ampere

Putaran RPM: 110 RPM

Tabel 4.3 data hasil uji coba motor trolley primer

\begin{tabular}{|c|c|c|c|c|c|c|c|}
\hline $\begin{array}{c}\text { Beban } \\
(\mathbf{K g})\end{array}$ & $\begin{array}{c}\text { Tegangan } \\
\text { (V) }\end{array}$ & Ia (A) & $\begin{array}{c}\text { Ra } \\
(\boldsymbol{\Omega})\end{array}$ & $\begin{array}{c}\boldsymbol{E} \boldsymbol{a} \\
\text { (V) }\end{array}$ & $\begin{array}{c}\text { Pm } \\
\text { (W) }\end{array}$ & $\begin{array}{c}\text { Effisiensi } \\
\text { (\%) }\end{array}$ & $\begin{array}{c}\text { Kecepatan } \\
\text { Putaran } \\
\text { Motor } \\
\text { (RPM) }\end{array}$ \\
\hline 0,2 & 11,54 & 0,0144 & 40,8 & 10,95248 & 0,158 & 94,9 & 100 \\
\hline 0,4 & 11,54 & 0,0288 & 40,8 & 10,36496 & 0,298 & 89,8 & 95 \\
\hline 0,6 & 11,54 & 0,0432 & 40,8 & 9,77744 & 0,422 & 84,7 & 90 \\
\hline 0,8 & 11,54 & 0,0576 & 40,8 & 9,18992 & 0,529 & 79,64 & 84 \\
\hline 1 & 11,54 & 0,072 & 40,8 & 8,6024 & 0,619 & 74,5 & 79 \\
\hline 1,2 & 11,54 & 0,0864 & 40,8 & 8,01488 & 0,693 & 69,5 & 74 \\
\hline 1,4 & 11,54 & 0,1008 & 40,8 & 7,42736 & 0,75 & 64,4 & 68 \\
\hline 1,6 & 11,54 & 0,1152 & 40,8 & 6,83984 & 0,788 & 59,3 & 63 \\
\hline 1,8 & 11,54 & 0,1296 & 40,8 & 6,25232 & 0,81 & 54,2 & 57 \\
\hline 2 & 11,54 & 0,144 & 40,8 & 5,6648 & 0,816 & 49,1 & 52 \\
\hline 2,2 & 11,54 & 0,1584 & 40,8 & 5,07728 & 0,804 & 44 & 47 \\
\hline 2,4 & 11,54 & 0,1728 & 40,8 & 4,48976 & 0,776 & 38,9 & 41 \\
\hline 2,6 & 11,54 & 0,1872 & 40,8 & 3,90224 & 0,73 & 33,8 & 36 \\
\hline
\end{tabular}

Sumber: Peneliti (2017)

Perhitungan gaya gerak listrik (Ea), daya mekanik $\left(P_{m}\right)$, efisiensi $(\eta)$, kecepatan putar motor (RPM).

a. Perhitungan emf (Ea)

$$
\begin{array}{ll}
\mathrm{V} & =\mathrm{Ea}+\mathrm{Ia} \cdot \mathrm{Ra} \\
11,54 \mathrm{~V} & =\mathrm{Ea}+0,1008 \times 40,8 \\
11,54 \mathrm{~V} & =\mathrm{Ea}+4.11264 \mathrm{~V} \\
\mathrm{Ea} & =11,54 \mathrm{~V}-4.11264 \mathrm{~V} \\
\mathrm{Ea} & =7.42736 \mathrm{~V}
\end{array}
$$

b. Perhitungan daya input

$$
\begin{array}{ll}
\text { Pin } & =\text { V } \times \text { Ia } \\
\text { Pin } & =11,54 \times 0,1008 \\
\text { Pin } & =1.16 \text { Watt }
\end{array}
$$

c. Perhitungan daya mekanik (Pm)

$$
\begin{array}{ll}
\mathrm{Pm} & =\text { Ea } \times \mathrm{Ia} \\
\mathrm{Pm} & =7.42736 \times 0,1008 \\
\mathrm{Pm} & =0,7486 \mathrm{Watt}
\end{array}
$$

d. Perhitungan Efisiensi $(n)$

$$
\begin{aligned}
\eta & =\frac{P_{\text {out }}}{P_{\text {in }}} \times 100 \% \\
\eta & =\frac{0,7486}{1,1632} \times 100 \% \\
\eta & =0,64356 \times 100 \% \\
& =64,4 \%
\end{aligned}
$$

e. Perhitungan kecepatan putar motor $(\mathrm{N})$

$$
\mathrm{N}=\frac{V_{T M-I_{a} \cdot R_{a}}}{K \Phi}
$$

Sesuai spesifikasi motor yang digunakan jika motor trolley primer tanpa beban maka diasumsikan $\mathrm{V}=$ Ea karena $\mathrm{Ia}=0$ dan putaran motor adalah 110 RPM. Maka perhitungan menjadi

$$
\begin{aligned}
& 110=\frac{12-(0 \times 123,8)}{110} \\
& 110=\frac{12-0}{K \Phi} \\
& K \Phi=\frac{12}{110} \\
& K \Phi=0,109 \text { Webber }
\end{aligned}
$$

Dari perhitungan diatas diperoleh besar $\mathrm{K} \varphi$ adalah sebesar 0,109 Webber. Maka perhi-tungan motor menjadi

$$
\begin{aligned}
N & =\frac{11,54-(0,1008 \times 40,8)}{0,109} \\
N & =\frac{11,54-4.11264}{0,109} \\
N & =\frac{7.42736}{0,109} \\
N & =68.140 \mathrm{RPM}
\end{aligned}
$$

Dari perhitungan diatas didapatkan putaran motor jika diberi beban 1,4 kg menjadi 68 putaran per menit (RPM).

\section{2) Motor Trolley Sekunder}

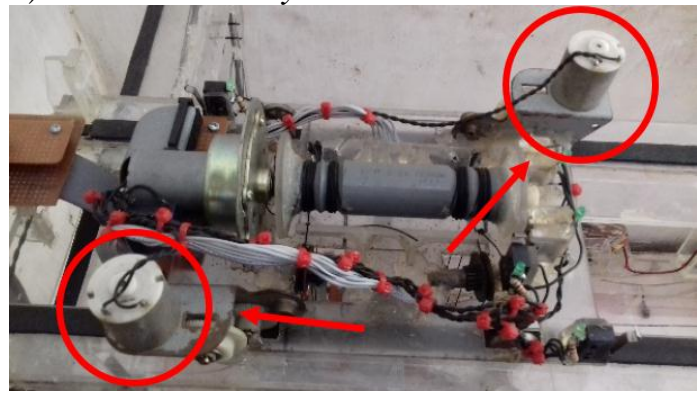

Gambar 4.4 Motor Trolley Sekunder Sumber: Peneliti (2017)

Spesifikasi Motor Trolley Sekunder Tipe : DC 25GA370 12V 450RPM Tegangan : DC 12 Volt 
Arus Kerja Maksimal : 3 Ampere Putaran RPM : 120 RPM

Tabel 4.6 data hasil uji coba motor trolley sekunder

\begin{tabular}{|c|c|c|c|c|c|c|c|}
\hline $\begin{array}{c}\text { Beban } \\
\text { (Kg) }\end{array}$ & $\begin{array}{c}\text { Tegangan } \\
\text { (V) }\end{array}$ & $\mathbf{I a}(\mathbf{A})$ & $\begin{array}{c}\text { Ra } \\
(\mathbf{\Omega})\end{array}$ & $\begin{array}{c}\boldsymbol{E} \boldsymbol{a} \\
(\mathrm{V})\end{array}$ & $\begin{array}{c}\text { Pm } \\
(\mathrm{W})\end{array}$ & $\begin{array}{c}\text { Effisiensi } \\
\mathbf{( \% )}\end{array}$ & $\begin{array}{c}\text { Kecepatan } \\
\text { Putaran } \\
\text { Motor } \\
\text { (RPM) }\end{array}$ \\
\hline 0,2 & 11,132 & 0,0224 & 4 & 11,0424 & 0,247 & 99,2 & 110 \\
\hline 0,4 & 11,132 & 0,0448 & 4 & 10,9528 & 0,491 & 98,4 & 109 \\
\hline 0,6 & 11,132 & 0,0672 & 4 & 10,8632 & 0,73 & 97,6 & 108 \\
\hline 0,8 & 11,132 & 0,0896 & 4 & 10,7736 & 0,965 & 96,8 & 107 \\
\hline 1 & 11,132 & 0,112 & 4 & 10,684 & 1,197 & 95,96 & 106 \\
\hline 1,2 & 11,132 & 0,1344 & 4 & 10,5944 & 1,424 & 95,17 & 105 \\
\hline 1,4 & 11,132 & 0,1568 & 4 & 10,5048 & 1,647 & 94,4 & 105 \\
\hline 1,6 & 11,132 & 0,1792 & 4 & 10,4152 & 1,866 & 93,6 & 104 \\
\hline 1,8 & 11,132 & 0,2016 & 4 & 10,3256 & 2,082 & 92,8 & 103 \\
\hline 2 & 11,132 & 0,224 & 4 & 10,236 & 2,293 & 91,95 & 102 \\
\hline 2.2 & 11,132 & 0,2464 & 4 & 10,1464 & 2,5 & 91,15 & 101 \\
\hline 2,4 & 11,132 & 0,2688 & 4 & 10,0568 & 2,703 & 90,34 & 100 \\
\hline 2,6 & 11,132 & 0,2912 & 4 & 9,9672 & 2,902 & 89,54 & 99 \\
\hline 2,8 & 11,132 & 0,3136 & 4 & 9,8776 & 3,098 & 88,73 & 98 \\
\hline 3 & 11,132 & 0,336 & 4 & 9,788 & 3,289 & 87,93 & 97 \\
\hline 3,2 & 11,132 & 0,3584 & 4 & 9,6984 & 3,476 & 87,12 & 96 \\
\hline 3,4 & 11,132 & 0,3808 & 4 & 9,6088 & 3,659 & 86,32 & 96 \\
\hline 3,6 & 11,132 & 0,4032 & 4 & 9,5192 & 3,838 & 85,51 & 95 \\
\hline 3,8 & 11,132 & 0,4256 & 4 & 9,4296 & 4,0136 & 84,71 & 94 \\
\hline
\end{tabular}

Sumber: Peneliti (2017)

Perhitungan gaya gerak listrik (Ea), daya mekanik $\left(P_{m}\right)$, efisiensi $(\eta)$, kecepatan putar motor (RPM).

a. Perhitungan emf (Ea)

$$
\begin{array}{ll}
\mathrm{V} & =\mathrm{Ea}+\mathrm{Ia} \cdot \mathrm{Ra} \\
11,132 \mathrm{~V} & =\mathrm{Ea}+0,112 \times 4 \\
11,132 \mathrm{~V} & =\mathrm{Ea}+0,448 \mathrm{~V} \\
\mathrm{Ea} & =11,132 \mathrm{~V}-0,448 \mathrm{~V} \\
\mathrm{Ea} & =10,684 \mathrm{~V}
\end{array}
$$

b. Perhitungan daya input

$$
\begin{aligned}
& \text { Pin }=\mathrm{V} \times \mathrm{Ia} \\
& \text { Pin }=11,132 \times 0,112 \\
& \text { Pin }=1,246784 \text { Watt }
\end{aligned}
$$

c. Perhitungan daya mekanik $(\mathrm{Pm})$

$$
\begin{aligned}
& \mathrm{Pm}=\mathrm{Ea} \times \mathrm{Ia} \\
& \mathrm{Pm}=10,684 \times 0,112 \\
& \mathrm{Pm}=1,196608 \mathrm{Watt}
\end{aligned}
$$

d. Perhitungan Efisiensi $(n)$

$$
\begin{aligned}
& \eta=P \_ \text {Out } / P \_ \text {in } \times 100 \% \\
& \eta=1,196608 / 1,246784 \times 100 \% \\
& \eta=0,95975 \times 100 \% \quad=95,9 \%
\end{aligned}
$$

e. Perhitungan kecepatan putar motor $(\mathrm{N})$

$$
\mathrm{N}=\frac{V_{T M-I_{a} \cdot R_{a}}}{K \Phi}
$$

Sesuai spesifikasi motor yang digunakan jika motor trolley sekunder tanpa beban maka diasumsikan $\mathrm{V}=$ Ea karena $\mathrm{Ia}=0$ dan putaran motor adalah 120 RPM. Maka perhitungan menjadi

$$
\begin{aligned}
& 120=\frac{12-(0 \times 4)}{120} \\
& 120=\frac{12-0}{K \Phi} \\
& K \Phi=\frac{12}{120} \\
& K \Phi=0,1 \text { Webber }
\end{aligned}
$$

Dari perhitungan diatas diperoleh besar $\mathrm{K} \varphi$ adalah sebesar 0,1 Webber. Maka perhitungan motor menjadi

$$
\begin{aligned}
& \mathrm{N}=\frac{11,32-(0,112 \times 4)}{0,1} \\
& \mathrm{~N}=\frac{11,132-0,48}{0,1} \\
& \mathrm{~N}=\frac{10,684}{0,1} \\
& \mathrm{~N}=106,84 \mathrm{RPM}
\end{aligned}
$$

Dari perhitungan diatas didapatkan putaran motor jika diberi beban $1 \mathrm{~kg}$ menjadi 107 putaran per menit (RPM).

\section{d. Perhitungan Tegangan Tali}

1) Kapasitas Angkat Crane

$\mathrm{Q}=\mathrm{Q}_{\text {total }}+\mathrm{Q}_{\text {preader }}+\mathrm{Q}_{\text {trolley }}$

$\mathrm{Q}=500 \mathrm{~g}+380 \mathrm{~g}+1120 \mathrm{~g}$

$\mathrm{Q}=2000$ gram

2) Tarikan Maksimum Tali

$\mathrm{S}=\frac{Q}{n \eta_{p} \cdot \eta_{1}}$

$\mathrm{S}=\frac{2000 \mathrm{~g}}{2 \times 0,873 \times 0,98}$

$\mathrm{S}=307,92$ gram

3) Nilai Tarikan Pada Satu Bagian Tali

$\mathrm{P}=\frac{\mathrm{Q}}{\mathrm{Z} \times \eta}$

$\mathrm{P}=\frac{2000 \mathrm{~g}}{8 \times 0,873 \text {. }}$

$\mathrm{P}=286,37$ gram

4) Nilai Beban Putus Pada Tali

$$
\begin{aligned}
S & =\mathrm{P} \times \mathrm{K} \\
& =286,37 \times 5,5 \\
& =1575,029 \text { gram }
\end{aligned}
$$

e. Hasil Pengalamatan dan Pemrograman PLC OMRON dengan software CX Programer 9.4

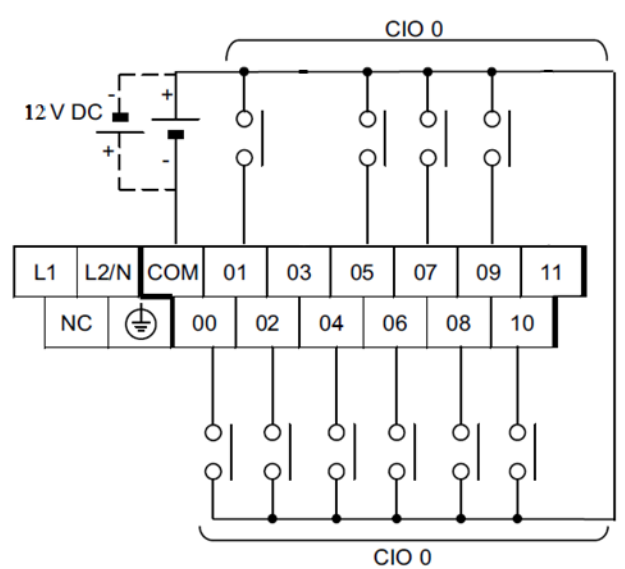

Gambar 4.6 Schematic Upper Terminal Block PLC. Sumber: Peneliti (2017) 


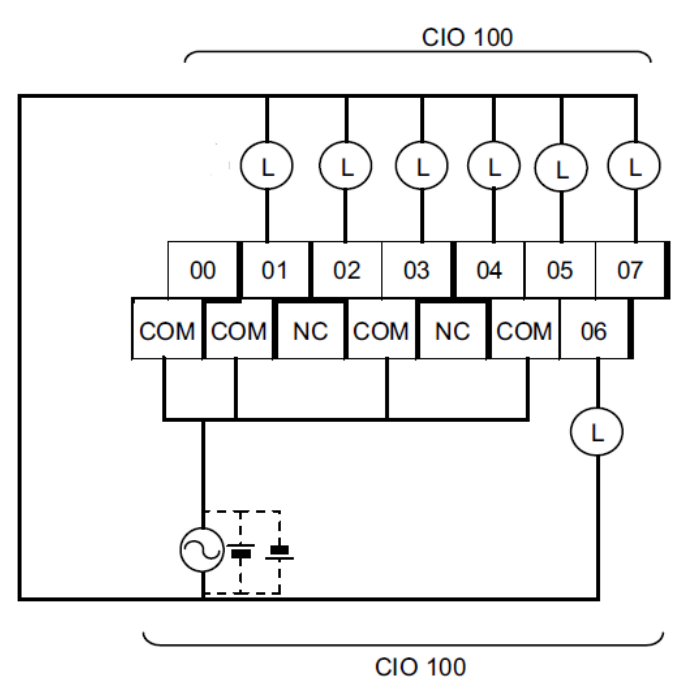

Gambar 4.7 Schematic Lower Terminal Block PLC Sumber: Peneliti (2017)

Tabel 4.1 Alamat I//O Software PLC

\begin{tabular}{|c|c|c|c|c|}
\hline Name & Data Type & Addres/Value & Usage & Comment \\
\hline RST CTLON & BOOL & 0.00 & In & Reset/Control On \\
\hline CTLOFSG & BOOL & 0.01 & In & Control Off Signal \\
\hline ESTPSG & BOOL & 0.02 & In & Emergency Stop Signal \\
\hline- & - & 0.03 & - & - \\
\hline OVLSG & BOOL & 0.04 & In & Overload Signal \\
\hline GATCLSG & BOOL & 0.05 & In & Gantry Anti-Collision Signal \\
\hline SPDLDSG & BOOL & 0.06 & In & Spreader Landed Signal \\
\hline HUPCMSG & BOOL & 0.07 & In & Hoist Up Cam Signal \\
\hline SPDLKUNSG & BOOL & 0.08 & In & Spreader Lock/Unlock Signal \\
\hline HDWCMSG & BOOL & 0.09 & In & Hoist Down Cam Signal \\
\hline BYPSSG & BOOL & 0.10 & In & By Pass Signal \\
\hline- & - & 0.11 & - & - \\
\hline CNLONIND & BOOL & 100.00 & Out & Control On Indicator \\
\hline GRNPMT & BOOL & 100.01 & Out & Gantry Run Permit \\
\hline HRNPMT & BOOL & 100.02 & Out & Hoist Rum Permit \\
\hline TRNPMT & BOOL & 100.03 & Out & Trolley Rum Permit \\
\hline BYPASS & BOOL & 100.04 & Out & By Pass Switch Active \\
\hline SPRNPMT & BOOL & 100.05 & Out & Spreader Run Permit \\
\hline HUPSTP & BOOL & 100.06 & Out & Hoist Up Stop \\
\hline HDWSTP & BOOL & 100.07 & Out & Hoist Down Stop \\
\hline
\end{tabular}

Sumber: Peneliti (2017)

Tabel 4.2 Alamat Relay Internal Software PLC.

\begin{tabular}{|c|c|c|c|c|}
\hline Name & Data Type & Addres/Value & Usage & Comment \\
\hline CTLON & BOOL & 1.05 & Work & Control On \\
\hline CTLONPMT & BOOL & 1.04 & Work & Control On Permit \\
\hline ESTPFLT & BOOL & 1.00 & Work & Emergency Stop Fault \\
\hline GATCLFLT & BOOL & 1.03 & Work & Gantry Anti-Collision Fault \\
\hline SPDUNKN & BOOL & 1.06 & Work & Spreader Status Unknown \\
\hline OVLFLT & BOOL & 1.01 & Work & Overload Fault \\
\hline
\end{tabular}

Sumber: Peneliti (2017)

1) Program Ladder PLC

$\square$ 硻 NewProject

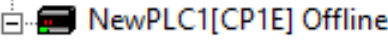

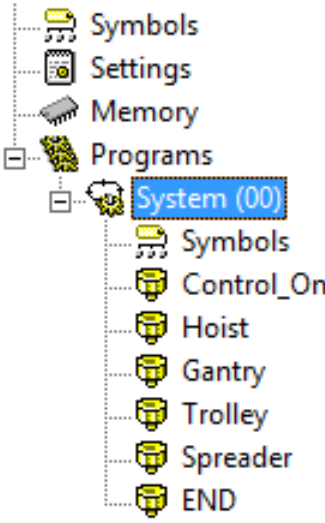

Gambar 4.5 Sistem PLC. Sumber: Peneliti (2017) (a) Sistem Control ON

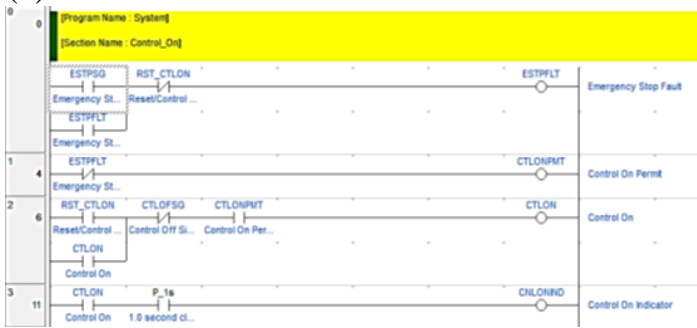

Gambar 4.6 Sistem Control On. Sumber: Peneliti (2017)

System Control On merupakan sebuah system yang akan mengawali dari setiap perintah pada semua system yang telah dibuat. System ini bekerja apabila inpu relay yang beralamat 0.00 (RST_CTLON) mendapatkan perintah input berupa tegangan $12 \mathrm{~V}$ DC menggunakan push button. Kemudian ketika alamat input tersebut mendapatkan perintah maka internal relay yang beralamat 1.05 (CTLON) akan aktif dan memberi perintah kepada senua system bahwa hardware siap untuk dioperasikan.

(b) Sistem Gantry

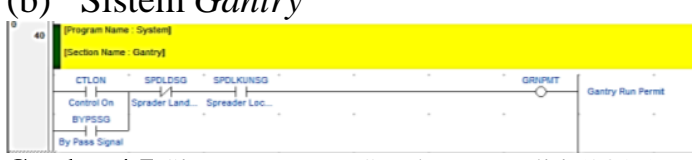

Gambar 4.7 Sistem Gantry. Sumber: Peneliti (2017)

Sistem gantry pada PLC merupakan suatu system yang memerintahkan eksternal relay pada rangkaian pengontrol gantry untuk aktif atau non aktif. Apaliba relay aktif berarti system gantry siap dioperasikan dan sebaliknya. Pada system ini terdapat beberapa input relay yang mempunyai fungsi sebagai pemutus rangkaian serta output relay sebagai perintah keluaran pada eksternal relay dalam rangkaian.

(c) Sistem Trolley

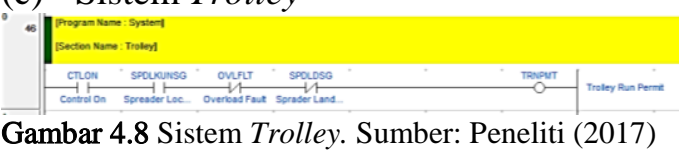

Sistem trolley pada PLC pada dasarnya hampir mirip dengan system gantry yaitu merupakan suatu system yang memerintahkan eksternal relay pada rangkaian pengontrol trolley untuk aktif atau non aktif. Apaliba relay aktif berarti system trolley siap dioperasikan dan sebaliknya. Pada system ini terdapat beberapa input relay yang mempunyai fungsi sebagai pemutus rangkaian serta output relay sebagai perintah keluaran pada eksternal relay dalam rangkaian. 
2) Rangkaian Kelistrikan

(a) Rangkaian Kelistrikan Sistem Trolley

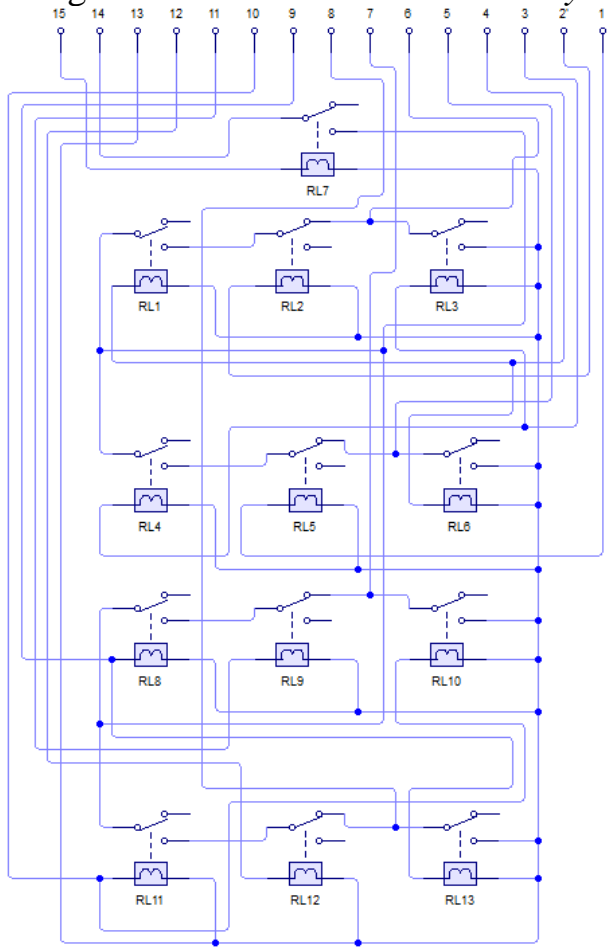

Gambar 4.9 Wiring Diagram Trolley

Sumber: Peneliti (2017)

Trolley adalah komponen pada electric container crane yang dapat bergerak maju dan mundur serta ke kanan dan ke kiri untuk meletakkan container pada slot dan row tertentu di container yard (CY).

Tabel 4.1 Tabel nomor pin wiring diagram trolley

\begin{tabular}{|c|c|l|}
\hline $\begin{array}{c}\text { Nomor } \\
\text { Pin }\end{array}$ & Fungsi & \multicolumn{1}{c|}{ Keterangan } \\
\hline 1 & Input & Limit switch trolley kiri stop \\
\hline 2 & Input & Limit switch trolley kanan stop \\
\hline 3 & Input & Console/ push button trolley kiri \\
\hline 4 & Input & Console/ push button trolley kanan \\
\hline 5 & Output & Supply untuk motor trolley bergerak ke kiri \\
\hline 6 & Output & Supply untuk motor trolley bergerak ke kanan \\
\hline 7 & Output & Supply untuk motor trolley bergerak maju \\
\hline 8 & Output & Supply untuk motor trolley bergerak mundur \\
\hline 9 & Input & Console/ push button trolley maju \\
\hline 10 & Input & Console/ push button trolley mundur \\
\hline 11 & Input & Limit switch trolley maju stop \\
\hline 12 & Input & Limit switch trolley mundur stop \\
\hline 13 & Input & Supply Tegangan negative (-) \\
\hline 14 & Input & Supply Tegangan positive (+) 12 V DC 3 A \\
\hline 15 & Input & Input trolley permit \\
\hline
\end{tabular}

Sumber: Peneliti (2017) (b) Rangkaian kelistrikan Sistem Gantry

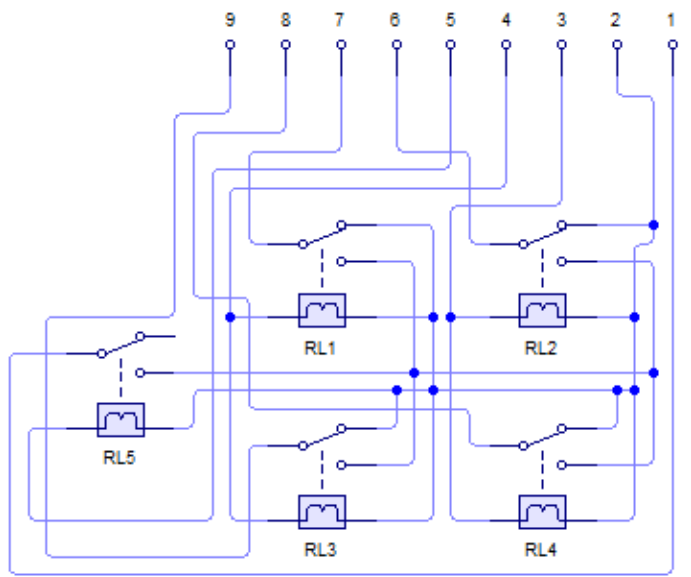

Gambar 4.10 Wiring Diagram Gantry Sumber: Peneliti (2017)

Gantry adalah komponen pada electric container crane yang bergerak kekanan dan kekiri beserta seluruk body electric container crane untuk menghampiri posisi container berada berdasarkan slot di container yard (CY). System gantry pada penelitian ini memiliki tambahan system cable track atau peenggulung kabel otomatis karena model crane pada penelitian ini dirancang tanpa menggunakan engine maka ditambah system tersebut supaya masih dapat bergerak fleksibel.

Tabel 4.2 Tabel nomor pin wiring diagram Gantry

\begin{tabular}{|c|c|l|}
\hline $\begin{array}{c}\text { Nomor } \\
\text { Pin }\end{array}$ & Fungsi & \multicolumn{1}{c|}{ Keterangan } \\
\hline 1 & Input & Supply Tegangan positive (+) 12 V DC 3 A \\
\hline 2 & Input & Supply Tegangan negative (-) \\
\hline 3 & Input & Console/ push button gantry kanan \\
\hline 4 & Input & Console / push button gantry kiri \\
\hline 5 & Input & Input gantry permit \\
\hline 6 & Output & Supply untuk motor gantry bergerak ke kanan \\
\hline 7 & Output & Supply untuk motor gantry bergerak ke kiri \\
\hline 8 & Output & Supply untuk motor cable track menggulung kabel \\
\hline 9 & Output & Supply untuk motor cable track mengulur kabel \\
\hline
\end{tabular}

Sumber: Peneliti (2017)

(c) Rangkaian Pengatur Kecepatan Motor

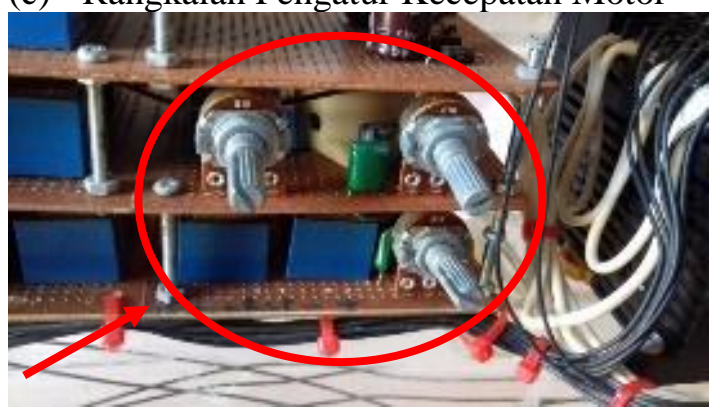

Gambar 4.11 Pengatur Kecepatan Motor.

Sumber: Peneliti (2017)

$\$$ 


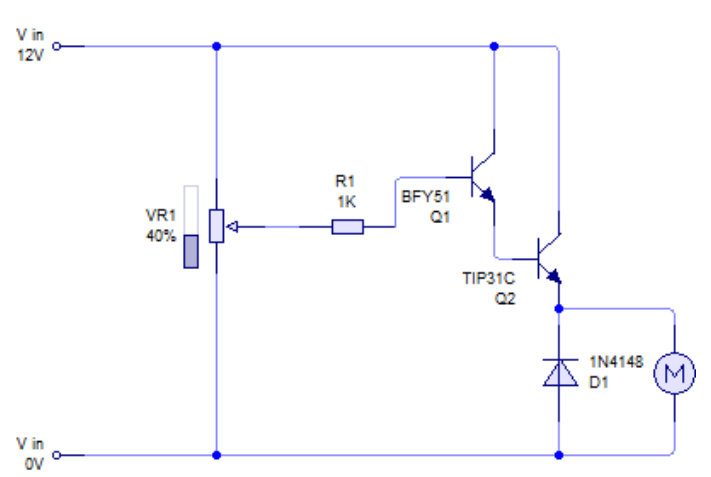

Gambar 4.12 Pengatur Kecepatan Motor. Sumber: Peneliti (2017)

Rangkaian pengatur kecepatan motor tersebut berperan untuk mengatur kecepatan putaran motor trolley, gantry dan cable track yang di rancang menggunakan 2 buah transistor yang dirangkai dengan cara darlington. Rangkaian pengatur kecepatan motor dengan transistor tersebut bisa mengatur putaran motor DC dari posisi diam sampai kecepatan maksimum. Dengan cara megatur jumlah pasokan tegangan yang mengalir ke motor.

(d) Rangkaian Power Supply AC to DC

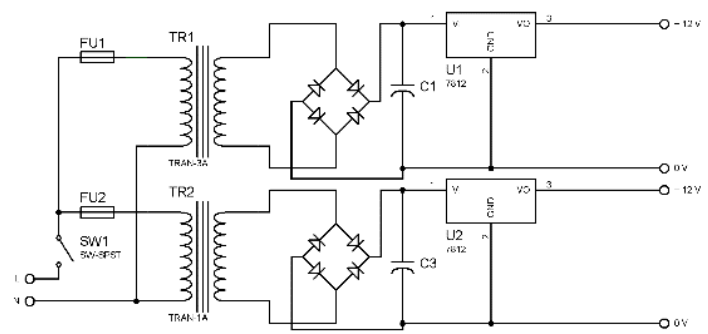

Gambar 4.13 Rangkaian Power Supply Sumber: Peneliti (2017)

Rangkaian power supply yang digunakan dalam penelitian terdapat 2 rangkaian power supply. Kedua rangkaian power supply disupply oleh satu sumber tegangan AC $220 \mathrm{~V}$ namun keluaran power supply tersebut berbeda yaitu 12 Volt DC dengan kuat arus 3 Ampere dan 12 Volt dengan kuat arus 1 Ampere.

\section{PENUTUP}

\section{a. Simpulan}

Hasil keluaran dan analisa penelitian dari beberapa system bertujuan supaya pengoperasian pada container crane dapat bergerak lebih fleksibel serta keselamatan kerja dapat terpenuhi. Maka dapat ditarik kesimpulan diantaranya:

1. Penambahan system double trolley dan system cable track menjadikan perge- rakan electric container crane dapat lebih fleksibel.

2. Program ladder dengan menggabungkan beberapa sistem yang ada pada spreader ke dalam sistem gantry dan trolley pada PLC Omron tipe CP1E E20SDR-A sebagai pengontrol sistem pengaman cukup efektif dalam merespon gangguan alat saat beroperasi sehingga meminimalkan resiko kecelakaan.

\section{b. Saran}

Pada kegiatan bongkar muat dipelabuhan setiap tahun terus mengalami peningkatkan. Diharapkan penelitian serta perkembangan sarana bongkar muat dipelabuhan seperti container crane harus dilanjutkan supaya setiap tahun container crane dapat ditingkatkan performanya dan tentunya kegiatan bongkar muat container dapat dengan cepat ditangani.

\section{DAFTAR PUSTAKA}

Anwar, 2015. Pengenalan Dasar PLC. https://anwarmekatronikapens.wordpres s.com/2015/04/22/plc/. 05/03/17 20.35

Budiyanto, M dan Wijaya, A., 2003. Pengenalan Dasar-Dasar PLC. Gaya Media. Yogyakarta.

Bolton, W., 2004. Progammable Logic Controller $(P L C)$. Erlangga. Jakarta

Dickson Kho, 2015. komponen Elektronika. http://teknikelektronika.com/pengertiansaklar-listrik-cara-kerjanya/. 07/03/17 10.15

Fahmizal, 2011. Driver Motor DC pada Robot Beroda dengan Konfigurasi H-BRIDGE. MOSFET.

https://fahmizaleeits.wordpress.com/201 1/12/04/driver-motordc-pada-robotberoda-dengan-konfigurasi-h-bridgemosfet/. 04/05/17 20.31.

Omron. 2013. General Specifications. https://www.ia.omron.com/products/fam ily/2064/specification.html. 05/03/17 20.35 .

Rahmawati Ati. 2015. Pengertian dan Jenis Alat Berat Crane. http://alatberat07.blogspot.co.id/2015/11/pengerti 
an-dan-jenis-alat-berat-crane.html. 05/03/17. 20.01

Rayen, 2015. Sensor Proximity. https://rayendente.wordpress.com/2015/ 06/22/sensor-proximity/. 07/05/17 13.31 .

Rudenko, N. 1992. Mesin Pemindah Bahan. (Edisi terjemahan) Cetakan pertama. Erlangga. Jakarta.

Sania, 2015. Instruksi-instruksi Dasar Pada PLC.

http://saniawd.blogspot.co.id/2015/05/i nstruksi-instruksi-dasar-pada-plc.html. 6/5/17 20.10.
Sumanto, 1994. Mesin Arus Searah. ANDI OFFSET. Yogyakarta.

Wicaksono, H., 2009. Programmable Logic controller, Teori Pemrograman dan Aplikasinya dalam otomasi sistem. Graha Ilmu. Yogyakarta

Wijayanto dan Susatio. 2012. Pengertian Gantry Crane.

Zuhal, 1998. Dasar Teknik Tenaga Listrik dan Elektronika Daya. Gramedia. Jakarta 